\title{
Microwave-Assisted Synthesis of Cross-Linked Co-poly(itaconic anhydride-methyl methacrylate): The Effects of the Molar Ratio and Cross-Linking Agent on the Thermal Stability
}

\author{
Ali Aldalbahi $\mathbb{D}^{\mathrm{D}}$, Mostafizur Rahaman, and Ayman El-Faham \\ Chemistry Department, College of Science, King Saud University, Riyadh 11451, Saudi Arabia \\ Correspondence should be addressed to Ali Aldalbahi; aaldalbahi@ksu.edu.sa
}

Received 6 December 2019; Revised 23 January 2020; Accepted 1 February 2020; Published 11 March 2020

Academic Editor: Jan-Chan Huang

Copyright (C) 2020 Ali Aldalbahi et al. This is an open access article distributed under the Creative Commons Attribution License, which permits unrestricted use, distribution, and reproduction in any medium, provided the original work is properly cited.

\begin{abstract}
In the present work, a new series of cross-linked copolymers based on itaconic anhydride and methyl methacrylate were prepared employing free radical copolymerization in the presence of azobisisobutyronitrile as an initiator and 2-butanone as a solvent under microwave irradiation. The copolymers containing itaconic anhydride (ITA) and methyl methacrylate (MMA) were chosen due to the formation of long-term stable anhydride moieties, which might be useful to attach enzymes covalently with numerous applications in water treatment. The copolymerization process was carried out in the presence of two types of cross-linking agent, namely, ethylene dimethacrylate (EDMA) and divinylbenzene (DVB) in a range of $0-20 \%(w / w)$ to explore their effect on the thermal and stiffness properties of the obtained cross-linked copolymers. Increasing the ratio of the cross-linking agent, the copolymers prefer to precipitate rather than form a gel during the polymerization process. While using ethylene dimethacrylate as a cross-linking agent, the copolymers change from porous to stiffness structures depending on the molar ratio of the monomers used during the polymerization. On the other hand, using divinylbenzene as a cross-linking agent, the stiffness structure was obtained in all cases and there is no effect observed for the monomer's ratio or the percentage of cross-linking agent on the morphology of the prepared copolymers.
\end{abstract}

\section{Introduction}

Microwave irradiation has become a common heat source in organic chemistry [1-5]. Inspired by this enormous success, the use of microwave irradiation is also recently increased for polymerization reactions [6-9]. The use of microwave irradiation in polymerization reactions enhanced the reactivity and selectivity as well as improves the reaction yield and the properties of the as-obtained polymers [2, 3, 7-10]. In addition, improving the overall properties of polymers such as their thermal and mechanical properties is a critical challenge in both their synthesis and applications [11].

The synthesis of cross-linked polymers is one way to improve the thermal and mechanical properties of polymers; the cross-linking density in the polymer network and the molecular weight of the polymers between the crosslinking points have an effect on the properties of cross-linked polymers [12-14].
Cross-linked polymers can be prepared via chemical (covalent or ionic bonds) or physical (hydrogen bonds, Van der Waals, or other interactions) cross-linking [12]. Chemical cross-linking polymerization is usually carried out in the presence of cross-linking agents to prepare highly crosslinked polymers with different degrees of cross-linking [14].

Itaconic anhydride (ITA) can be obtained from renewable resources such as plants produced from the fermentation of carbohydrates, which forms itaconic acid that can be converted into anhydride via dehydration or by the pyrolysis of citric acid [15]. Polymers and copolymers based on ITA can be prepared via free radical reaction polymerization [16-21].

In addition, ITA has extensively been used in industrial applications as comonomer, for instance, as an essential for rubber materials, paints and colors, coatings, biodegradable polymers, contact lenses, or medicinal applications [22, 23]. The anhydride groups exist in the copolymers containing 
ITA normally used to immobilize enzymes via the reaction of amino groups with the anhydride-containing copolymer [24-30]. Itaconic anhydride (ITA) has been also used as a monomer with various vinyl monomers such as vinyl chloride [31-33], acrylonitrile, vinyl acetate, 2-chloroethyl acrylate [31, 34], and styrene [33-35]. Moreover, Miles et al. [20] reported that poly(ITA) exhibited good adhesion to silicon surfaces and behaved as a positive-acting electron-beam resist material [20]. The same authors [31] reported the synthesis of thermally cross-linked methyl methacrylate- (MMA-) based copolymer, containing ITA, which was investigated as alternative thermally crosslinkable resist material [31].

In addition, methyl methacrylate (MMA) comonomer provides mechanical stability for the copolymer and chemical resistance against a number of organic solvents. Furthermore, it has advantages of poly(methyl methacrylate) (PMA), which is considered to have good adhesion to different surfaces and the transparency coating [36].

Accordingly, the present work represents the synthesis of a new series of cross-linked copolymers based on different ratios of ITA and MMA using a microwave irradiation. Samples of copolymers were prepared using various types of cross-linking agents and different degrees of crosslinking to explore their effect on the thermal properties and the morphology of the as-obtained cross-linked polymers. Two types of cross-linking agents, ethylene dimethacrylate (EDMA) and divinylbenzene (DVB), were used with the degree of cross-linking in the range of $0-20 \%(w / w)$. The structure, thermal properties, and surface morphology of the crosslinked polymers were also studied.

\section{Materials and Methods}

Methyl methacrylate (MMA), itaconic anhydride (ITA), ethylene dimethacrylate (EDMA), divinylbenzene (DVB), and $N, N^{\prime}$-azobisisobutyronitrile (AIBN) were supplied from Sigma-Aldrich (Chemie GmbH, 82024 Taufkirchen, Germany). AIBN was recrystallized from absolute ethanol prior to use. All solvents were dried before use.

A microwave (Monowave 300, Aton Paar $\mathrm{GmbH}$, $1400 \mathrm{~W}$ maximum magnetron, Germany) with a maximum filling volume of 6 and $20 \mathrm{~mL}$ for 10 and $30 \mathrm{~mL}$ vials, respectively. Maximum operating pressure of $30 \mathrm{bar}$, maximum IR temperature of $300^{\circ} \mathrm{C}$, maximum fibre-optic temperature of $300^{\circ} \mathrm{C}$, and maximum power of $850 \mathrm{~W}$ were used. The vials were constructed from borosilicate glass and silicon carbide using PEEK caps and Teflon-coated silicone seals.

2.1. Characterization. The functional groups of the prepared cross-linked copolymers were investigated by Fouriertransform infrared (FT-IR) spectroscopy. The thermal properties were studied using thermogravimetric analysis (Q500 TGA, USA) under nitrogen atmosphere within the temperature range 30 to $800^{\circ} \mathrm{C}$ and at the heating rate $10^{\circ} \mathrm{C} / \mathrm{min}$. The morphology of the prepared copolymers was studied using scanning electron microscopy (SEM). The specific surface area and the pore size distribution were investigated by applying Brunauer-Emmett-Teller (BET) theory and
Barrett-Joyner-Halenda (BJH) model using Micromeritics (ASAP-2020, USA) at the temperature $77 \mathrm{~K}$.

2.2. General Procedure for Copolymer Synthesis. Cross-linked copolymers were prepared using microwave-assisted method (Monowave 300, Anton Paar) as described elsewhere [37, 38]. In a typical reaction, itaconic anhydride (ITA) was mixed with methyl methacrylate (MMA) at different molar ratios in the presence of 5\% $(w / w)$ AIBN using 2-butanone $(6 \mathrm{~mL})$ as solvent and different amounts of EDMA or DVB as the cross-linking agent $(5,10,15$, and $20 \%, w / w)$ in $20 \mathrm{~mL}$ reaction vial, as shown in Table 1 . The individual vials were fixed by screwing down the upper rotor plate and finally closed with the protective hood. The reaction vials were heated to $120^{\circ} \mathrm{C}$ for $5 \mathrm{~min}$, were held at the same temperature for $5 \mathrm{~min}(\sim 12-13$ bar pressure, $5-6 \mathrm{~W})$, and then were cooled using a fan for $5 \mathrm{~min}$.

The precipitated final products, DPMITA 1-5, EPMITA 1-5, EPMITA 1-10, EPMITA 1-15, and EPMITA 1-20, were washed with diethyl ether and dried in a vacuum oven at $40^{\circ} \mathrm{C}$ for $24 \mathrm{~h}$.

The other final products, DPMITA 1-10, DPMITA 1-15, and DPMITA 1-20, were washed with acetone, and dried in a vacuum oven at $40^{\circ} \mathrm{C}$ for $24 \mathrm{~h}$.

\section{Results and Discussion}

3.1. Copolymer Synthesis. Various copolymer compositions can produce a very large number of different arrangements, producing materials of varying chemical and physical properties. Thus, the hydrophilicity of copolymers can be modified by changing the amount of incorporated itaconic anhydride [22]. These amphiphilic polymers, at which the copolymers contain both hydrophilic and hydrophobic segments, have considerable attention in different applications as in biological systems [27], medicinal chemistry [30], water treatment, and heavy metal removal [39].

Different ratios of itaconic anhydride (ITA) and methyl methacrylate (MMA) were mixed in 2-butanone as solvent in the presence of AIBN (5\%) as an initiator for $5 \mathrm{~min}$ at $120^{\circ} \mathrm{C}$ using a microwave-assisted free radical copolymerization (Scheme 1).

It was noticed that the polymer preferred to form a precipitate rather gel during the copolymerization process upon increasing the ratio of the cross-linking agent at a monomer ratio of MMA : ITA = 1:2 using EDMA as the cross-linking agent and with monomer ratio of (MMA : ITA = 1:1) using DVB as crosslinking agent (Figures 1 and 2, respectively). Moreover, formation of precipitated copolymer rather than the gel is favoured during the reaction upon increasing the amount of MMA in the copolymer (Figure 2).

3.2. FT-IR Spectroscopy and Elemental Analysis. The FTIR spectra of the different compositions of ITA and MMA (EPMITA and DPMITA) in the presence of different crosslinking agents ethylene dimethacrylate and divinylbenzene were studied. The copolymer ITA-MMA (EPMTITA) using ethylene dimethacrylate showed characteristic bands at 1863 and $1783 \mathrm{~cm}^{-1}$ for ITA $(\mathrm{C}=\mathrm{O})$ (symmetric and 
TABLE 1: Summary of the copolymer's ratio and yield.

\begin{tabular}{|c|c|c|c|c|c|c|c|}
\hline Copolymer code & $\begin{array}{l}\text { Cro } \\
\text { ag }\end{array}$ & $\begin{array}{l}\text { linking } \\
(\% / g)\end{array}$ & MMA/ITA ratio & MMA (g/mmol) & ITA (g/mmol) & $\mathrm{AIBN}^{*}(\mathrm{~g})$ & Yield (g) \\
\hline EPMITA 1-5 & \multirow{8}{*}{ EDMA } & $5 / 0.1621$ & \multirow{4}{*}{$1: 2$} & \multirow{4}{*}{$1.0012 / 10$} & \multirow{4}{*}{$2.2416 / 20$} & 0.1702 & 0.85 \\
\hline EPMITA $1-10$ & & $10 / 0.3243$ & & & & 0.1784 & 2.56 \\
\hline EPMITA 1-15 & & $15 / 0.4864$ & & & & 0.1864 & 2.15 \\
\hline EPMITA 1-20 & & $20 / 0.6486$ & & & & 0.1945 & 1.80 \\
\hline EPMITA 2-15 & & $15 / 0.3183$ & \multirow{2}{*}{$1: 1$} & \multirow{2}{*}{$1.0012 / 10$} & \multirow{2}{*}{$1.1208 / 10$} & 0.1220 & 1.70 \\
\hline EPMITA 2-20 & & $20 / 0.4244$ & & & & 0.1273 & 1.90 \\
\hline EPMITA 3-15 & & $15 / 0.4685$ & \multirow{2}{*}{$2: 1$} & \multirow{2}{*}{$2.0024 / 20$} & \multirow{2}{*}{$1.1208 / 10$} & 0.1795 & 2.10 \\
\hline EPMITA 3-20 & & $20 / 0.6246$ & & & & 0.1874 & 2.84 \\
\hline DPMITA 1-5 & \multirow{8}{*}{ DVB } & $5 / 0.1621$ & \multirow{4}{*}{$1: 2$} & \multirow{4}{*}{$1.0012 / 10$} & \multirow{4}{*}{$2.2416 / 20$} & 0.1702 & 1.20 \\
\hline DPMITA 1-10 & & $10 / 0.3243$ & & & & 0.1784 & 2.80 \\
\hline DPMITA 1-15 & & $15 / 0.4864$ & & & & 0.1864 & 1.80 \\
\hline DPMITA 1-20 & & $20 / 0.6486$ & & & & 0.1945 & 2.52 \\
\hline DPMITA 2-5 & & $5 / 0.1061$ & \multirow{2}{*}{$1: 1$} & \multirow{2}{*}{$1.0012 / 10$} & \multirow{2}{*}{$1.1208 / 10$} & 0.1114 & 1.60 \\
\hline DPMITA 2-10 & & $10 / 0.2122$ & & & & 0.1167 & 1.80 \\
\hline DPMITA 3-5 & & $5 / 0.1562$ & \multirow{2}{*}{$2: 1$} & \multirow{2}{*}{$2.0024 / 20$} & \multirow{2}{*}{$1.1208 / 10$} & 0.1717 & 2.20 \\
\hline DPMITA 3-10 & & $10 / 0.3123$ & & & & 0.1717 & 2.40 \\
\hline
\end{tabular}

$* 5 \%(w / w)$.

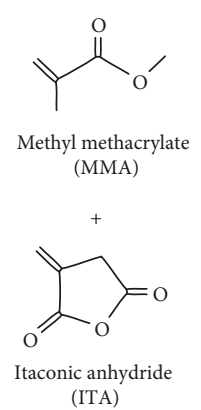

(ITA)

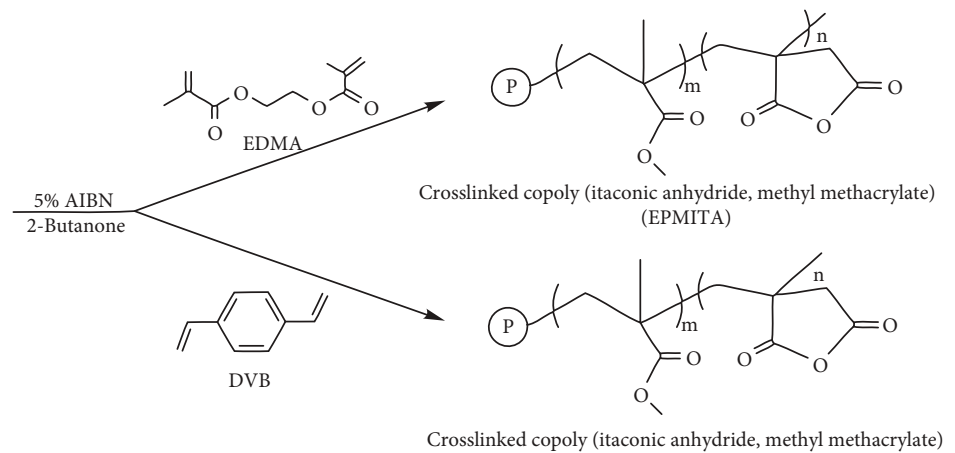

(DPMITA)

Scheme 1: Copolymerization of itaconic anhydride and methyl methacrylate in the presence of ethylene dimethacrylate (EDMA) and divinylbenzene (DVB) as cross-linking agents.

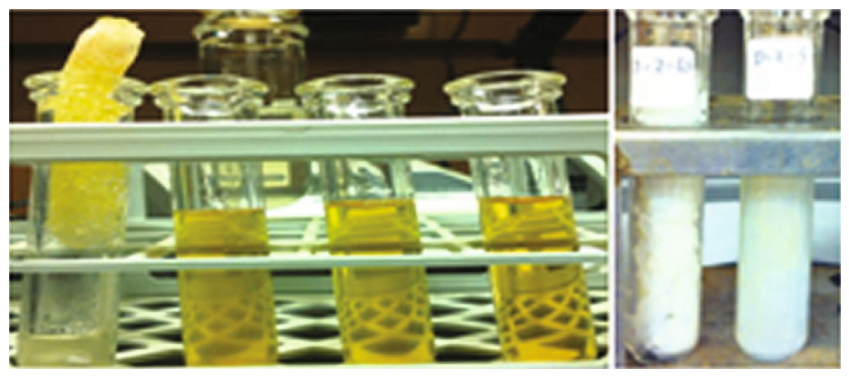
(a)
(b)
(c)
(d)
(e)
(f)

Figure 1: Photograph of the (a) EPMITA 1-20, (b) EPMITA 1-15, (c) EPMITA 1-10, (d) EPMITA 1-5, (e) DPMITA 2-5, and (f) DPMITA 2-10 copolymers.

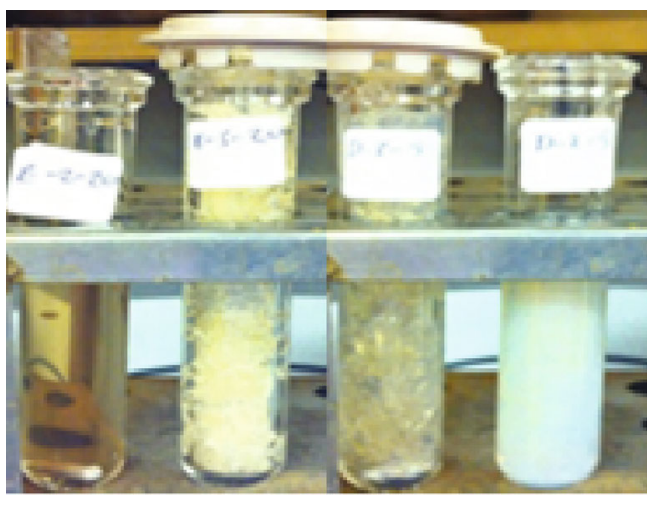
(a)
(b)
(c)
(d)

Figure 2: Photograph of the (a) EPMITA 2-20, (b) EPMITA 3-20, (c) DPMITA 3-5, and (d) DPMITA 2-5 copolymers. 


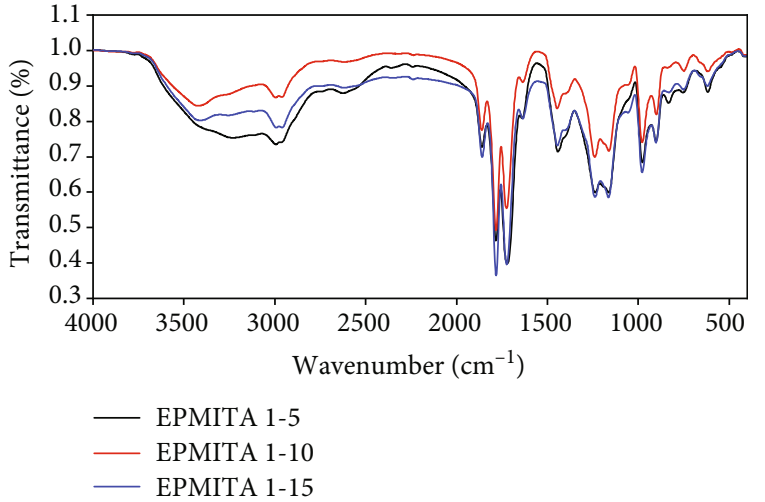

(a)

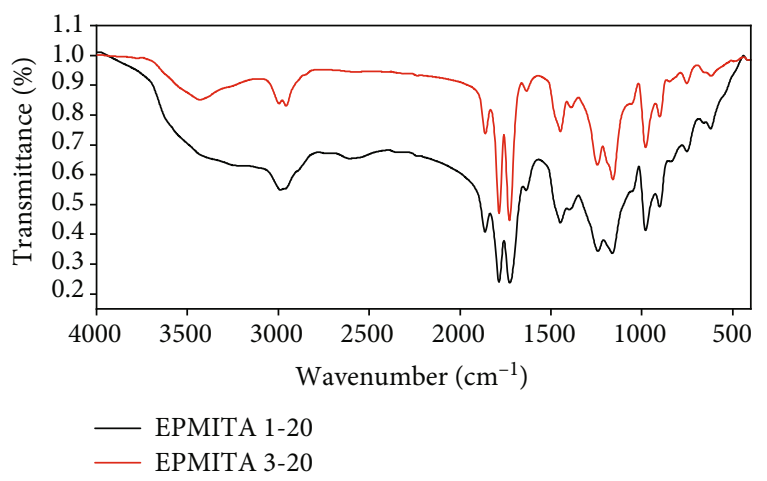

(c)

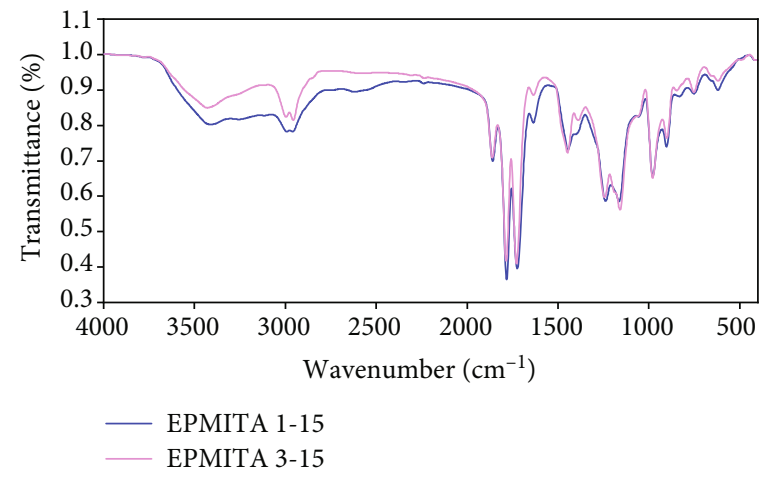

(b)

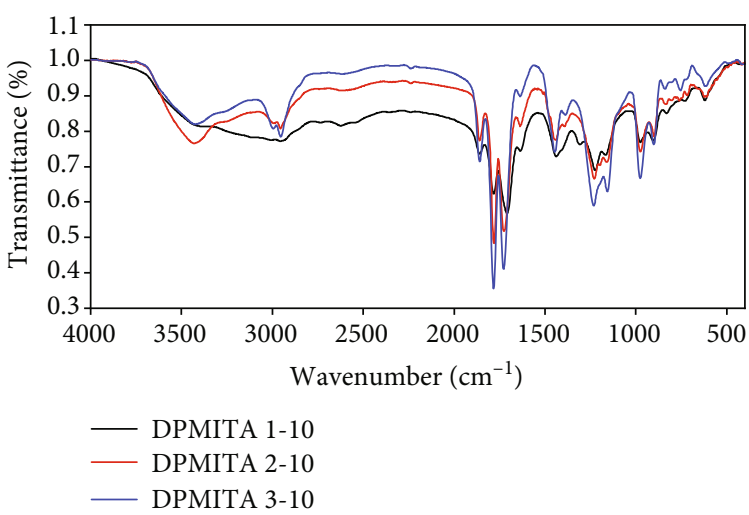

(d)

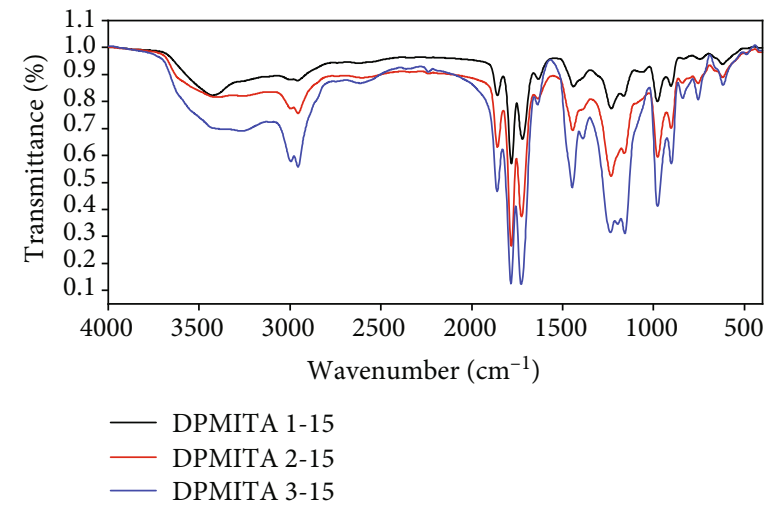

(e)

FIGURE 3: FT-IR of EPMITA and DPMITA copolymers: (a) EPMITA 1-5, EPMITA 1-10, and EPMITA 1-15; (b) EPMITA 1-15 and EPMITA 3-15; (c) EPMITA 1-20 and EPMITA 3-20; (d) DPMITA 1-10, DPMITA 2-10, and DPMITA 3-10; (e) DPMITA 1-15, DPMITA 2-15, and DPMITA 3-15.

asymmetric stretching of the carbonyl in the 5-membered anhydride ring) and $1724-1728 \mathrm{~cm}^{-1}$ for the stretching carbonyl group of the ester corresponding to MMA residue, beside a characteristic band at $1640 \mathrm{~cm}^{-1}$ related to the stretching $\mathrm{C}=\mathrm{O}$ ester of the cross-linking agent (EDMA) (Figures 3(a)-3(c)). The intensity of the cross-linking agent was increased as the ratio increased as observed from Figures 3(a)-3(c) (Table 2). The copolymer MMA-co-ITA (DPMTITA) using DVB as cross-linking agent showed the same characteristic bands at 1863 and $1782 \mathrm{~cm}^{-1}$ for ITA $(\mathrm{C}=\mathrm{O})$ (symmetric and asymmetric stretching of the carbonyl in the 5-membered anhydride ring) and 1709$1728 \mathrm{~cm}^{-1}$ for the stretching carbonyl group of the ester corresponding to MMA residue, beside a characteristic band at $1631-1640 \mathrm{~cm}^{-1}$ related to the stretching $\mathrm{CH}=\mathrm{CH}$ aromatic related to the cross-linking agent (DVB) (Figures 3(d)-3(e), Table 2).

The FTIR of ITA-MMA copolymers' results indicated that during the microwave process, the itaconic anhydride moieties were not disrupted in the copolymer backbone chain, which is in accordance with the previously reported data $[15,27]$. 
TABLE 2: FT-IR peaks observed for the EPMITA and DPMITA copolymers.

\begin{tabular}{|c|c|c|c|}
\hline \multirow{2}{*}{ Functional group } & \multirow{2}{*}{ Peak assignment } & \multicolumn{2}{|c|}{ Wavenumber $\left(\mathrm{cm}^{-1}\right)$} \\
\hline & & EPMITA copolymers & DPMITA copolymers \\
\hline \multirow{2}{*}{ Aliphatic } & C-H stretching of methyl & $2955-2958$ & 2954-2957 \\
\hline & Aliphatic backbone stretching & $1437-1451$ & $1438-1449$ \\
\hline \multirow{3}{*}{ Carbonyl group } & $\mathrm{C}=\mathrm{O}$ stretching (anhydride) $(\mathrm{C}=\mathrm{O}$ symmetric and asymmetric) & $1783-1863$ & $1780-1782$ \\
\hline & $\mathrm{C}=\mathrm{O}$ stretching methyl methacrylate & $1724-1728$ & $1709-1728$ \\
\hline & $\mathrm{C}=\mathrm{O}$ stretching (ester) EDMA & $1636-1640$ & - \\
\hline Ether & Stretching vibration of C-O-C & $1160-1242$ & $1155-1232$ \\
\hline \multirow{3}{*}{ Aromatic } & Aromatic C-H stretch & - & 2995-3004 \\
\hline & Aromatic $=\mathrm{CH}$ stretch & - & $1631-1640$ \\
\hline & Aromatic $=\mathrm{CH}$ bending & - & $618-899$ \\
\hline
\end{tabular}

TABLE 3: Information derived from the TGA of the degradation of the EPMITA and DPMITA copolymers.

\begin{tabular}{|c|c|c|c|c|c|c|c|c|}
\hline \multirow{3}{*}{$\begin{array}{l}\text { Copolymer code } \\
\text { EPMITA 1-5 }\end{array}$} & \multicolumn{4}{|c|}{$\begin{array}{l}\text { Distribution of volatile ranges } \\
\text { (temperature range) }\left({ }^{\circ} \mathrm{C}\right)\end{array}$} & \multirow{3}{*}{$\frac{T_{\text {onset }}\left({ }^{\circ} \mathrm{C}\right)}{168}$} & \multirow{3}{*}{$\frac{T_{\max }\left({ }^{\circ} \mathrm{C}\right)}{248}$} & \multirow{3}{*}{$\frac{T_{50}\left({ }^{\circ} \mathrm{C}\right)}{340}$} & \multirow{3}{*}{$\begin{array}{c}\text { Residue (\%) } \\
17.13\end{array}$} \\
\hline & $30-150$ & $150-230$ & $230-349$ & $349-600$ & & & & \\
\hline & $6.7 \%$ & $17.7 \%$ & $27.0 \%$ & $32.2 \%$ & & & & \\
\hline \multirow{2}{*}{ EPMITA 1-10 } & $30-142$ & $142-229$ & 229-339 & $339-600$ & \multirow{2}{*}{228} & \multirow{2}{*}{387} & \multirow{2}{*}{377} & \multirow{2}{*}{18.88} \\
\hline & $4.0 \%$ & $12.4 \%$ & $26.6 \%$ & $37.9 \%$ & & & & \\
\hline \multirow{2}{*}{ EPMITA 1-15 } & $30-137$ & $137-225$ & $225-331$ & $331-600$ & \multirow{2}{*}{244} & \multirow{2}{*}{390} & \multirow{2}{*}{371} & \multirow{2}{*}{13.80} \\
\hline & $2.7 \%$ & $14.1 \%$ & $25.2 \%$ & $43.7 \%$ & & & & \\
\hline \multirow{2}{*}{ EPMITA 1-20 } & $30-99$ & $99-215$ & $215-342$ & $342-600$ & \multirow{2}{*}{254} & \multirow{2}{*}{399} & \multirow{2}{*}{394} & \multirow{2}{*}{12.13} \\
\hline & $0.7 \%$ & $13.8 \%$ & $25.7 \%$ & $47.7 \%$ & & & & \\
\hline \multirow{2}{*}{ EPMITA 2-15 } & $30-100$ & $100-231$ & $231-329$ & $329-600$ & \multirow{2}{*}{231} & \multirow{2}{*}{388} & \multirow{2}{*}{381} & \multirow{2}{*}{11.00} \\
\hline & $1.4 \%$ & $10.9 \%$ & $25.1 \%$ & $51.3 \%$ & & & & \\
\hline \multirow{2}{*}{ EPMITA 2-20 } & $30-100$ & $100-235$ & $235-329$ & $329-600$ & \multirow{2}{*}{236} & \multirow{2}{*}{390} & 385 & 075 \\
\hline & $1.1 \%$ & $12.9 \%$ & $23.0 \%$ & $52.9 \%$ & & & 380 & 9.15 \\
\hline FPMITA $3-15$ & $30-100$ & $100-149$ & $149-323$ & $323-600$ & 222 & 380 & 380 & 880 \\
\hline ЕРИН1 & $0.5 \%$ & $2.3 \%$ & $29.3 \%$ & $59.7 \%$ & 222 & 300 & 300 & 0.00 \\
\hline ЕРМITA 20 & $30-100$ & & & $326-600$ & 253 & 387 & 300 & 720 \\
\hline ЕРИП1 А $3-20$ & $0.6 \%$ & & & $61.2 \%$ & 253 & $30 \%$ & 390 & 1.29 \\
\hline DPMITA $1-5$ & $30-164$ & $164-231$ & $231-345$ & $345-600$ & 188 & 401 & 384 & 1884 \\
\hline DPMHА & $6.3 \%$ & $11.1 \%$ & 25.5 & $38.0 \%$ & 188 & 401 & 384 & 18.84 \\
\hline DPMITA 1 & $30-199$ & $199-257$ & $257-350$ & $350-600$ & 140 & 408 & 370 & 1640 \\
\hline DPMH A $1-10$ & $20.4 \%$ & $12.1 \%$ & 14.4 & $36.5 \%$ & 140 & 408 & 370 & 10.49 \\
\hline DPMITA 115 & $30-243$ & & & $371-600$ & 143 & 412 & 422 & 2048 \\
\hline DFIVII A $1-1$ - & $12.5 \%$ & & & $46.6 \%$ & 143 & 412 & 422 & 20.40 \\
\hline DPMITA 2-5 & $30-200$ & & & $342-600$ & 200 & 396 & 400 & 2030 \\
\hline & $7.5 \%$ & & & $43.8 \%$ & 200 & 390 & 400 & 20.50 \\
\hline 10 & $30-143$ & & & $341-600$ & 212 & 400 & & \\
\hline DPVIIIA $2-10$ & $11.5 \%$ & & & $47.3 \%$ & 212 & 400 & 399 & 16.56 \\
\hline DPMIT A 35 & $30-130$ & $130-238$ & $238-329$ & $329-600$ & 238 & 382 & $381+2+3$ & 1256 \\
\hline DPIVII A $3-5$ & $5.5 \%$ & $4.8 \%$ & 22.4 & $53.1 \%$ & 230 & 302 & 304 & 12.50 \\
\hline DDMITA 231 & $30-194$ & & & $333-600$ & 263 & 301 & 300 & 1414 \\
\hline DPMIIA $3-10$ & $1.8 \%$ & & & $54.7 \%$ & 203 & 391 & 398 & 14.14 \\
\hline
\end{tabular}

$*$ At $600^{\circ} \mathrm{C}$. 


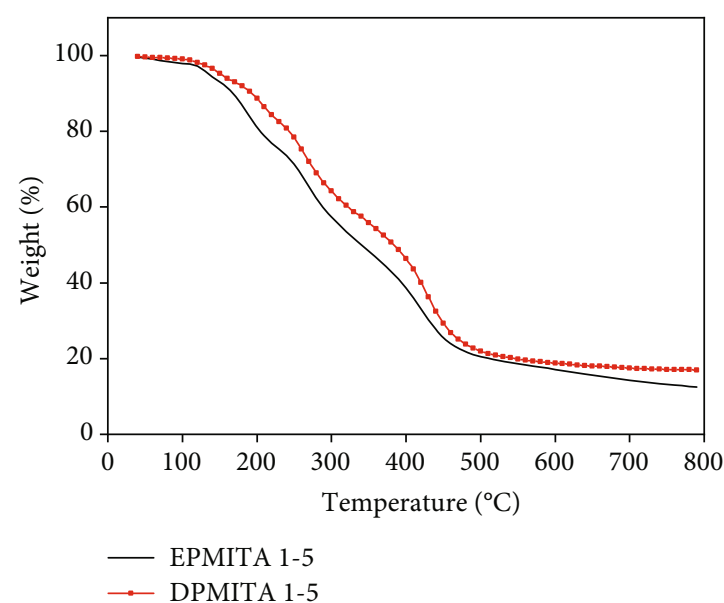

(a)

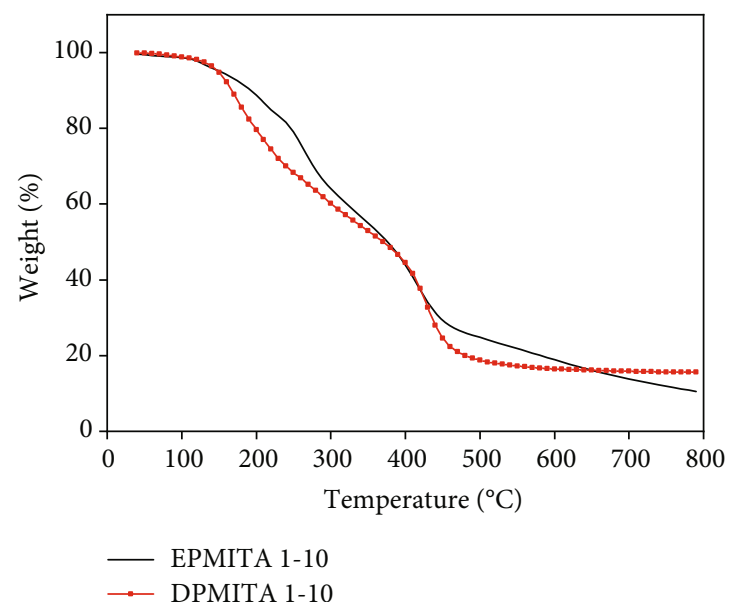

(b)

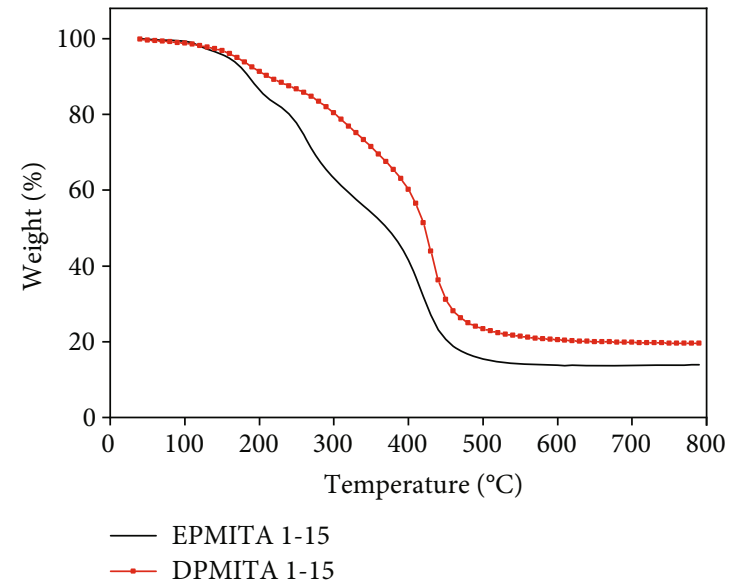

(c)

FIgURE 4: TGA curves recorded for the different copolymers: (a) EPMITA 1-5 and DPMITA 1-5; (b) EPMITA 1-10 and DPMITA 1-10; (c) EPMITA 1-15 and DPMITA 1-15 showing the effect of the type of cross-linking agent used.

3.3. Thermogravimetric Analysis. Thermogravimetric analysis of the prepared copolymers is shown in Table 3 and Figures 4 and 5. Degradation takes place in four steps for copolymers EPMITA 1-5, EPMITA 1-10, EPMITA 1-15, EPMITA 1-20, EPMITA 2-5, EPMITA 2-10, EPMITA 2-15, EPMITA 2-20, EPMITA 3-5, EPMITA 3-10, EPMITA 3-15, DPMITA 1-5, DPMITA 1-10, and DPMITA 3-5 and in three steps for copolymers EPMITA 3-20, DPMITA 1-15, DPMITA 2-5, DPMITA 2-10, and DPMITA 2-10. It was observed that the first step might be attributed to the evaporation of residual water and decarboxylation of the anhydride groups [15]. The next steps involve the degradation of the ester linkages in the side chains, followed by the degradation of the cross-linking agent [15]. Finally, the copolymer backbone is degraded generally at $>300^{\circ} \mathrm{C}$ leaving a residue at $600^{\circ} \mathrm{C}$ of $7.3-18.9$ and $12.6-20.5 \%$ for the EPMIA and DPMITA copolymers, respectively. The amount of residue depends on the copolymer composition as well as the type of cross-linking agent used. The DPMITA copolymers show higher residue due to the use of an aromatic cross-linking agent.
3.4. Effect of the Type of Cross-Linking Agents. The EPMITA copolymers showed high thermal stability when using $>10 \%(w / w)$ of the cross-linking agent, and the decomposition was independent of the ITA content. Moreover, the thermal stability was $251-3^{\circ} \mathrm{C}$ and the maximum degradation of the copolymers was in the range of $380-399^{\circ} \mathrm{C}$, which was not affected by the copolymer composition. The thermal stability reached a maximum at $258^{\circ} \mathrm{C}$ for the EPMITA 2-20 copolymer containing $20 \%(w / w)$ of the cross-linking agent. The copolymer composition may affect the amount of residue, which increased upon increasing the ITA content and decreasing the amount of cross-linking agent used.

On the other hand, the thermal stability of the DPMITA copolymers is affected by the copolymer composition as well as the percentage of cross-linking agent used. A significant increase in the thermal stability was observed upon increasing the ITA content with the onset temperature increasing from 140 to $212^{\circ} \mathrm{C}$, reaching a maximum at $263^{\circ} \mathrm{C}$ for the DPMITA 1-10, DPMITA 2-10, and DPMITA 3-10 copolymers, respectively. The same results, obtained for DPMITA 


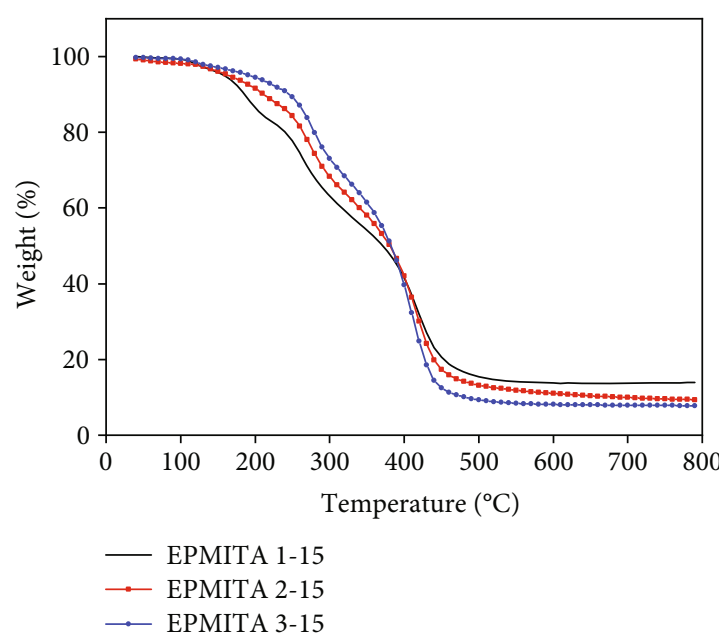

(a)

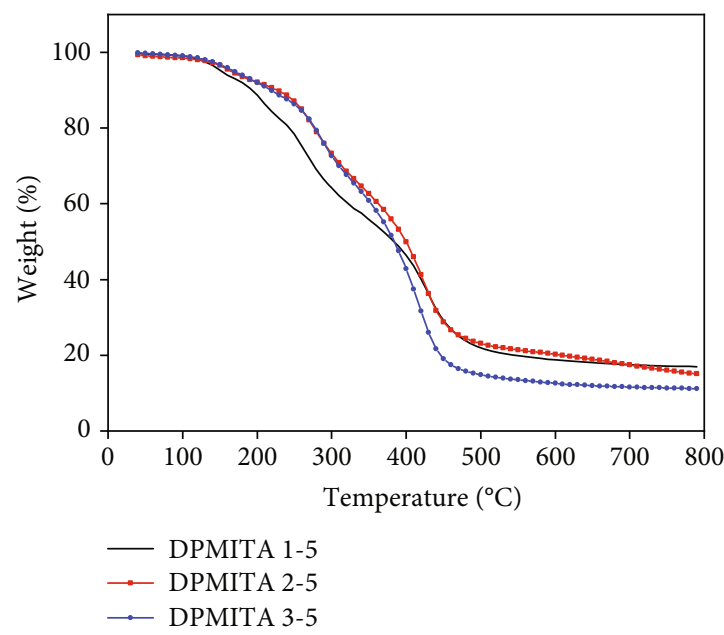

(c)

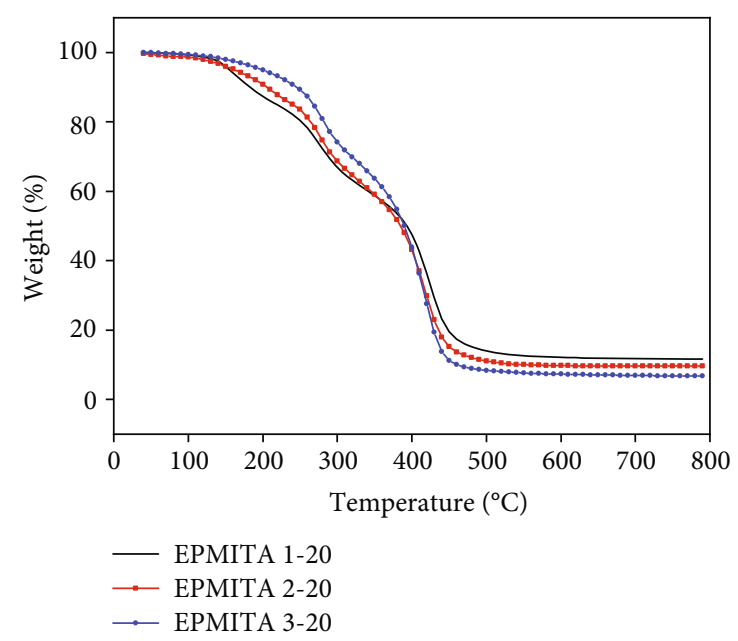

(b)

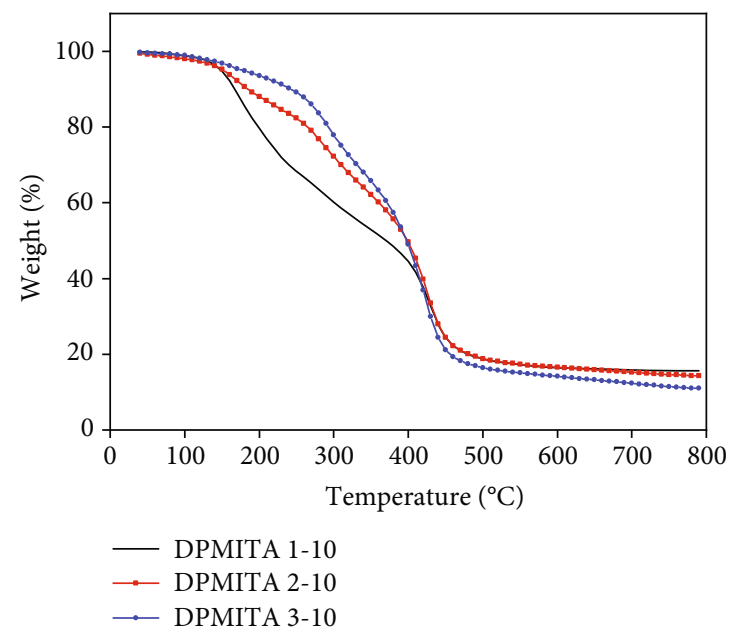

(d)

Figure 5: TGA curves recorded for the different copolymers: (a) EPMITA 1-15, EPMITA 2-15, and EPMITA 3-15; (b) EPMITA 1-20, EPMITA 2-20, and EPMITA 3-20; (c) DPMITA 1-5, DPMITA 2-5, and DPMITA 3-5; (d) DPMITA 1-10, DPMITA 2-10 and DPMITA 3-10 showing the effect of the monomer molar ratio used.

1-5, DPMITA 2-5, and DPMITA 3-5, made clear that the thermal stability decreased upon increasing the percentage of cross-linking agent used.

3.5. SEM for Copolymers. The morphological structures of the copolymers EPMITA 1-15, EPMITA 2-15, and EPMITA 315, EPMITA 1-20, EPMITA 2-20, EPMITA 3-20 (Figure 6), DPMITA 1-5, DPMITA 2-5, and DPMITA 3-5, DPMITA 1-10, DPMITA 2-10, and DPMITA 3-10 were observed using SEM (Figure 7).

In regard to series A (Figure 6), by changing the molar ratio of the monomers used MMA/ITA from $1: 2$ to $1: 1$, porous structures were obtained, while by increasing the amount of MMA (EPMITA 3-15) in the copolymer, the porosity decreased leading to stiffness structures, which may be attributed to the postcross-linking process in the copolymer. This structure was formed because MMA is a good candidate for the cross-linking process, which is observed as rapid precipitation during the copolymer synthesis [27].
On the other hand, from series A to series B (Figure 7), the roughness increases upon increasing the percentage of cross-linking agent (EDMA) used from 15 to $20 \%(w / w)$, which indicates the presence of a high degree of crosslinking in the copolymer.

In the case of using DVB as the cross-linking agent, stiffness structure was formed in all cases and there was no effect due to the monomer ratio or the percentage of cross-linking agent used on the morphology of the asprepared copolymers $[40,41]$.

3.6. Surface Area and Pore Size Analysis. According to the SEM images, EPMITA 1-15 and EPMITA 2-15 showed a porous structure. Therefore, both samples were selected to analyse the surface area and type of pores and pore volume by BET. The BET surface area and pore size distribution are displayed in Figure 8. The specific surface areas of EPMITA 1-15 and EPMITA 2-15 are determined to be 1.04 and $1.18 \mathrm{~m}^{2} / \mathrm{g}$, respectively; whereas the pore volumes are 0.0063 and $0.017 \mathrm{~cm}^{3} / \mathrm{g}$, respectively. This result is consistent 


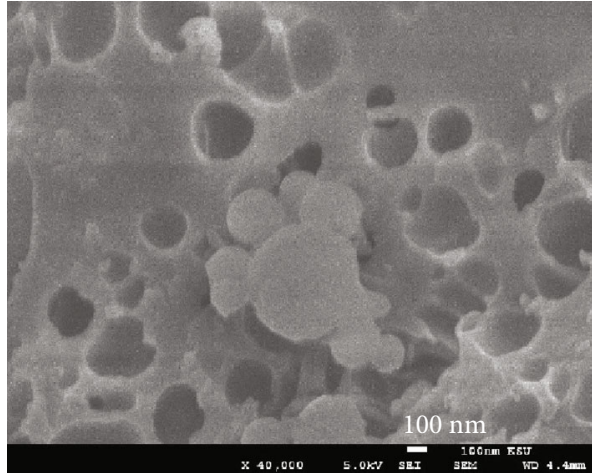

(a)

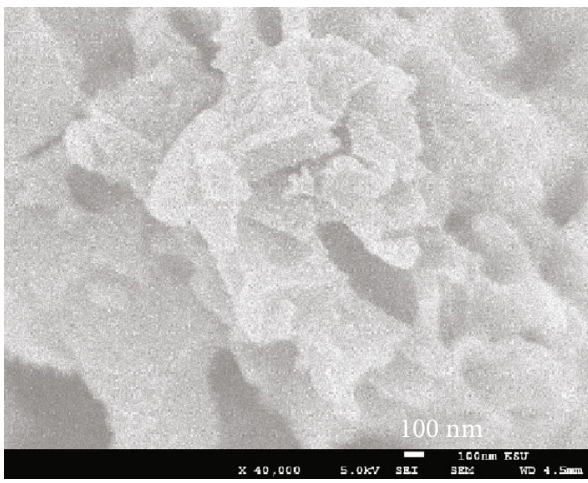

(c)

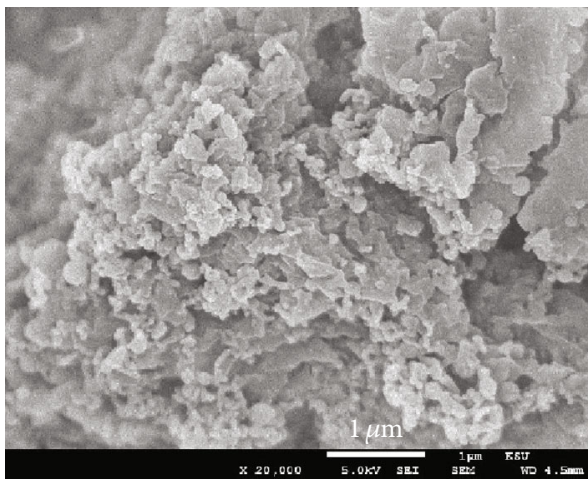

(e)

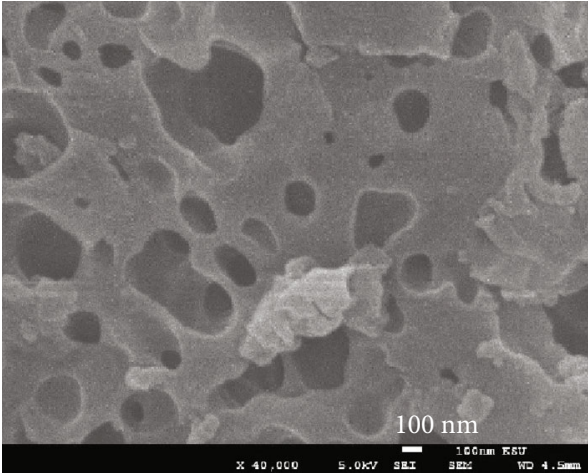

(b)

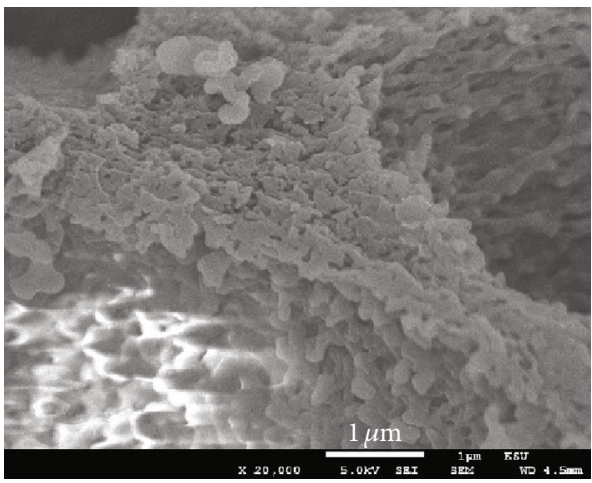

(d)

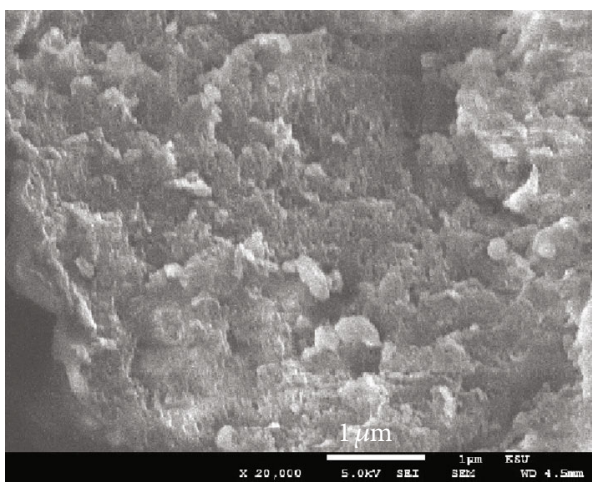

(f)

FIGURE 6: SEM images of the different copolymers: (a) EPMITA 1-15, (b) EPMITA 2-15, (c) EPMITA 3-15, (d) EPMITA 1-20, (e) EPMITA 220, and (f) EPMITA 3-20 showing the effect of the monomer molar ratio, type, and percentage of the cross-linking agent used.

with the SEM images, which have proved that the structure of EPMITA 2-15 was more porous than EPMITA 1-15. The analysis of pore size distribution by the Barrett-JoynerHalenda (BJH) method [42] showed that EPMITA 1-15 and EPMITA 2-15 have a mesoporous and macroporous structure. The pore size distribution of both samples has a wide range from 2 to $90 \mathrm{~nm}$ with the average pore sizes 26.6, and $25.3 \mathrm{~nm}$ for EPMITA 1-15 and EPMITA 2-15, respectively.

3.7. Prospective Applications. The above-going discussions and the results obtained for EPMITA 1-15 and EPMITA 215 copolymers indicate that these possess a mesoporous and macroporous structure with average pore sizes of 26.6, and $25.3 \mathrm{~nm}$, respectively. Hence, these obtained data could be useful for application in water purification technology.

\section{Conclusions}

Cross-linking has been used to improve the solubility, stiffness, mechanical strength, and rigidity of polymers for some potential applications. Itaconic anhydride-based copolymers were prepared with methyl methacrylate in the presence of two types of cross-linking agents, EDMA and DVB, via a microwave-assisted synthesis. The FTIR results indicated that the microwave process did not disrupt the itaconic anhydride moieties in the copolymer backbone chain. The formation of a cross-linked copolymer is favoured rather than a gel 


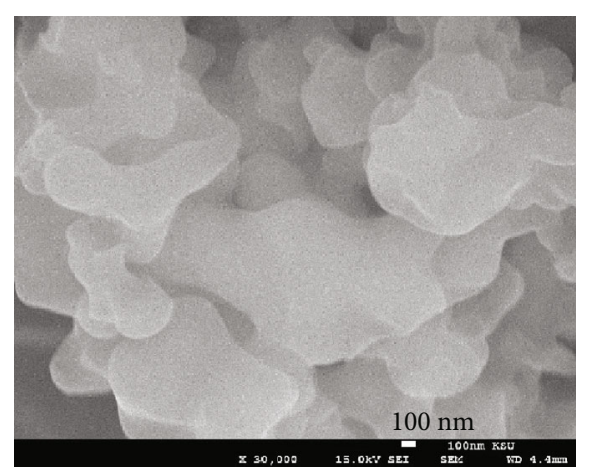

(a)

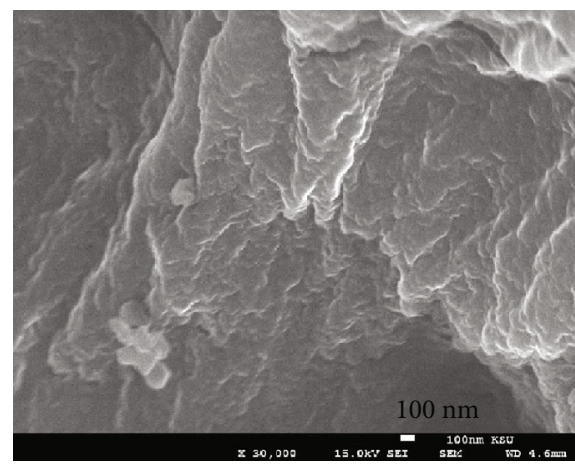

(c)

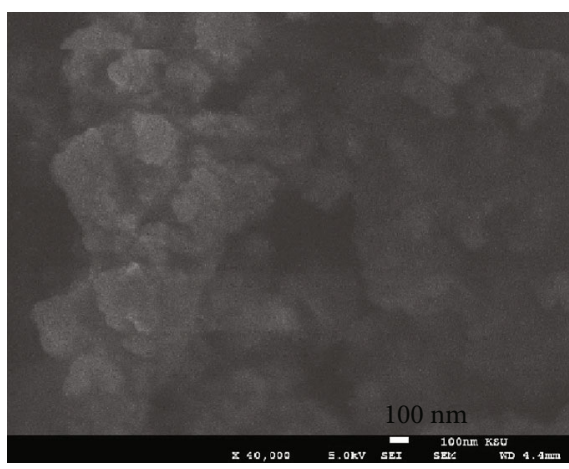

(e)

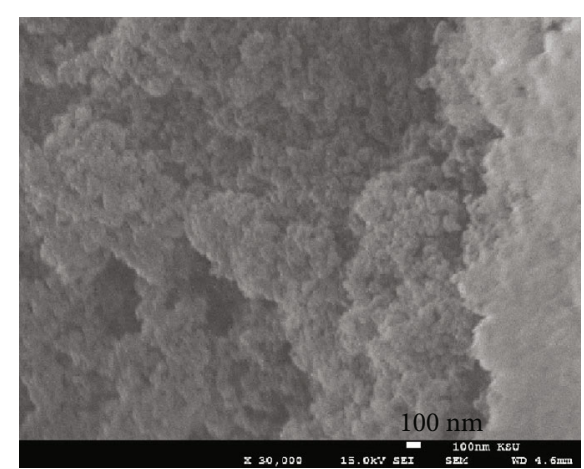

(b)

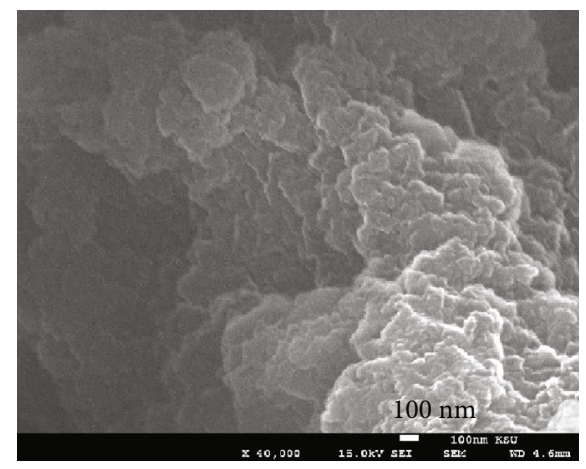

(d)

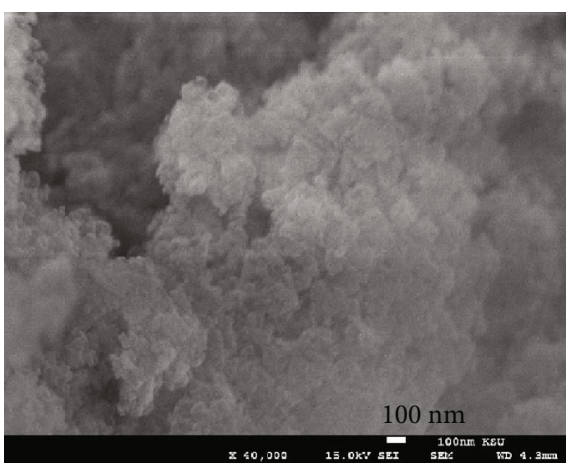

(f)

Figure 7: SEM images of the different copolymers: (a) DPMITA 1-5, (b) DPMITA 2-5, (c) DPMITA 3-5, (d) DPMITA 1-10, (e) DPMITA 210, and (f) DPMITA 3-10 showing the effect of the monomer molar ratio, type, and percentage of the cross-linking agent used.

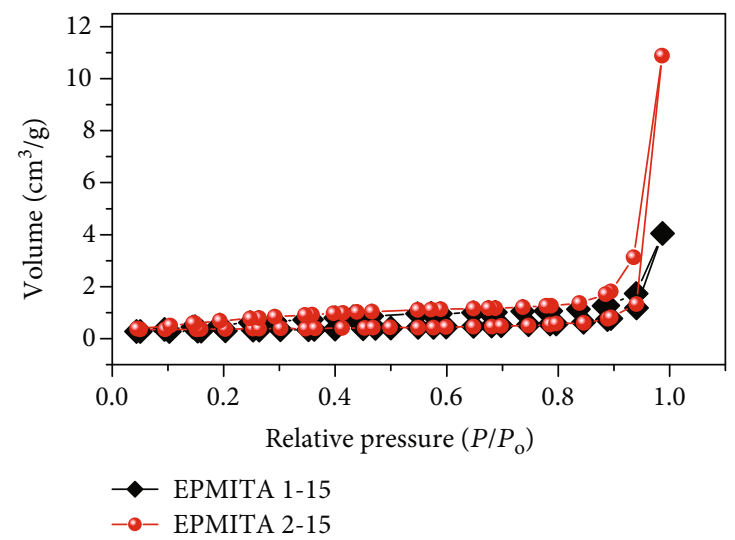

(a)

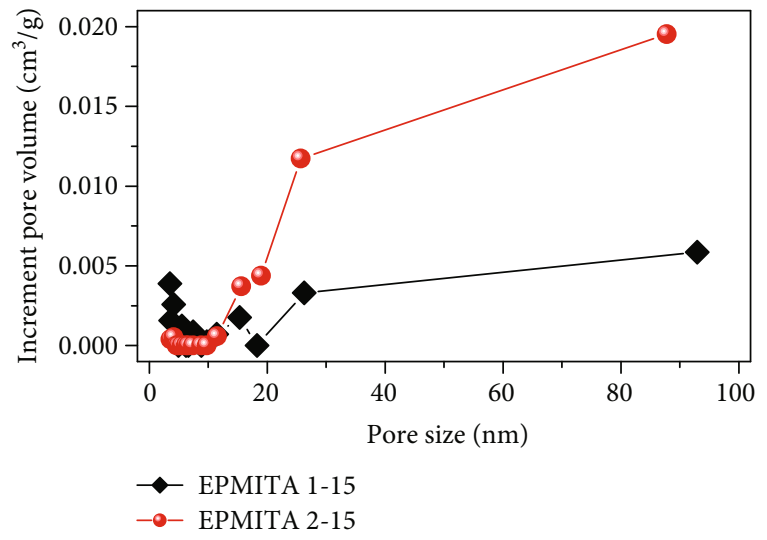

(b)

FIgURE 8: (a) $\mathrm{N}_{2}$ adsorption/desorption isotherms and (b) pore size distribution by the BJH method. 
during the polymerization process upon increasing the amount of MMA in the copolymer. The EPMITA copolymers show high thermal stability when prepared using $>10 \%(w / w)$ of the cross-linking agent, and its decomposition was independent of the ITA content. For the DPMITA copolymers, the thermal stability increased upon increasing the ITA content. The prepared copolymers showed different morphological structures depending on the monomer ratio and type of cross-linking agent used. EPMITA 1-15 and EPMITA 2-15 have porous structures and become stiff upon increasing the ratio of MMA in the copolymer (EPMITA 315). For the DPMITA copolymers, there was no effect due to the monomer ratio or the percentage of DVB used on the morphology of the as-obtained copolymers, which all showed a stiffness structure. In general, stiffness structures for the copolymers are observed upon increasing the percentage of cross-linking agent used. Moreover, EPMITA 1-15 and EPMITA 2-15 have a mesoporous and macroporous structure with average pore sizes of 26.6 , and $25.3 \mathrm{~nm}$, respectively. These data obtained could be useful for some applications in water purifications.

\section{Data Availability}

The data used to support the findings of this study are available from the corresponding author upon request.

\section{Conflicts of Interest}

The author declares that there is no conflict of interest.

\section{Acknowledgments}

The authors would like to extend their sincere appreciation to the Deanship of Scientific Research at King Saud University, Saudi Arabia, for funding this work (RG-1436-005).

\section{References}

[1] S. Mallakpour, F. Tirgir, and M. R. Sabzalian, "Synthesis and structural characterization of novel biologically active and thermally stable poly(ester-imide)s containing different natural amino acids linkages," Journal of Polymer Research, vol. 18, no. 3, pp. 373-384, 2011.

[2] F. Wiesbrock, R. Hoogenboom, C. H. Abeln, and U. S. Schubert, "Single-mode microwave ovens as new reaction devices: accelerating the living polymerization of 2-ethyl-2-oxazoline," Macromolecular Rapid Communications, vol. 25, no. 22, pp. 1895-1899, 2004.

[3] S. Mallakpour and Z. Rafiee, "An efficient microwave-assisted synthesis of optically active polyamides in the presence of ionic liquid and conventional solvent: a comparative study," Polymer Bulletin, vol. 66, no. 8, pp. 1005-1014, 2011.

[4] B. L. Hayes, "Recent advances in microwave assisted synthesis," Aldriach Chimica Acta, vol. 37, no. 2, pp. 66-76, 2004.

[5] C. Oliver Kappe, "My twenty years in microwave chemistry: from kitchen ovens to microwaves that aren't microwaves," Chemical Record, vol. 19, no. 1, pp. 15-39, 2018.

[6] C. Koopmans, M. Iannelli, P. Kerep et al., "Microwave-assisted polymer chemistry: Heck-reaction, transesterification, Baeyer-
Villiger oxidation, oxazoline polymerization, acrylamides, and porous materials," Tetrahedron, vol. 62, no. 19, pp. 4709-4714, 2006.

[7] S. Mallakpour and Z. Rafiee, "Application of microwaveassisted reactions in step-growth polymerization: a review," Iranian Polymer Journal, vol. 17, no. 12, pp. 907-935, 2008.

[8] D. Bogdal and A. Prociak, Microwave-Enhanced Polymer Chemistry and Technology, Blackwell, Oxford, UK, 2007.

[9] T. Iwamura, K. Ashizawa, K. Adachi, and M. Takasaki, "Anionic hydrogen-transfer polymerization ofN-isopropylacrylamide under microwave irradiation," Journal of Polymer Science Part A: Polymer Chemistry, vol. 57, no. 24, pp. 24152419, 2019.

[10] A. Borriello, L. Nicolais, X. Fang, S. J. Huang, and D. A. Scola, "Synthesis of poly(amide-ester)s by microwave methods," Journal of Applied Polymer Science, vol. 103, no. 3, pp. 19521958, 2007.

[11] G. Babaladimath and V. Badalamoole, "Silver nanocomposite hydrogel of Gum Ghatti with potential antibacterial property," Journal of Macromolecular Science, Part A, vol. 56, no. 10, pp. 952-959, 2019.

[12] Y. Song, L. Wang, R. Gyanda et al., "Effect of the crosslink functionality on the mechanical properties of crosslinked 1,2,3-triazole polymers as potential binders for rocket propellants," Journal of Applied Polymer Science, vol. 117, no. 1, pp. 473-478, 2010.

[13] R. Fan, Y. Zhang, C. Huang, Y. Zhang, Y. Fan, and K. Sun, "Effect of crosslink structures on dynamic mechanical properties of natural rubber vulcanizates under different aging conditions," Journal of Applied Polymer Science, vol. 81, no. 3, pp. 710-718, 2001.

[14] B. M. Edward, In integrated Product and Process Design and Development: the Product Realization Process, CRC Press, Boca Raton, FL, 2nd edition, 1977.

[15] S. Shang, S. J. Huang, and R. A. Weiss, "Synthesis and characterization of itaconic anhydride and stearyl methacrylate copolymers," Polymer, vol. 50, no. 14, pp. 3119-3127, 2009.

[16] M. A. R. Meier, J. O. Metzger, and U. S. Schubert, "Plant oil renewable resources as green alternatives in polymer science," Chemical Society Reviews, vol. 36, no. 11, pp. 1788-1802, 2007.

[17] S. Ishida and S. Saito, "Polymerization of itaconic acid derivatives," Journal of Polymer Science Part A-1: Polymer Chemistry, vol. 5, no. 4, pp. 689-705, 1967.

[18] V. D. Papanu, "Amide-imide derivatives of homopolymers of itaconic anhydride having antitumour activity: EP," Monsanto Co, USA, 1983.

[19] T. Otsu and H. Watanabe, "Radical polymerization reactivity of dialkyl itaconates and characterization of their polymers," European Polymer Journal, vol. 29, no. 2-3, pp. 167-174, 1993.

[20] A. F. Miles, J. M. G. Cowie, R. H. Bennett, and D. R. Brambley, "New thermally crosslinkable electron-beam resists: 1 . Itaconic anhydride- methyl methacrylate copolymers," Polymer, vol. 32, no. 3, pp. 484-488, 1991.

[21] J. A. Wallach and S. J. Huang, "Copolymers of itaconic anhydride and methacrylate-terminated poly(lactic acid) macromonomers," Biomacromolecules, vol. 1, no. 2, pp. 174-179, 2000.

[22] G. T. Tsao, P. Ouyang, and J. Chen, Biotechnology in China II: Chemicals, Energy and Environment, Springer-Verlag, Berlin Heidelberg, Heidelberg, 2010. 
[23] L. Cismaru, T. Hamaide, and M. Popa, "Itaconic anhydride based amphiphilic copolymers: synthesis, characterization and stabilization of carboxyl functionalized, PEGylated nanoparticles," European Polymer Journal, vol. 43, no. 12, pp. 4843-4851, 2007.

[24] T. Pompe, K. Salchert, K. Alberti, P. Zandstra, and C. Werner, "Immobilization of growth factors on solid supports for the modulation of stem cell fate," Nature Protocols, vol. 5, no. 6, pp. 1042-1050, 2010.

[25] W. Tischer and F. Wedekind, "Immobilized enzymes: methods and applications," in Biocatalysis-from discovery to application, pp. 95-126, Springer Verlag, Berlin Heidelberg, 1999.

[26] F. Müller, B. Torger, P. J. Allertz et al., "Multifunctional crosslinkable itaconic acid copolymers for enzyme immobilization," European Polymer Journal, vol. 102, pp. 47-55, 2018.

[27] M. B. Milovanovic, S. S. Trifunovic, L. Katsikas, and I. G. Popović, "Preparation and modification of itaconic anhydride-methyl methacrylate copolymers," Journal of the Serbian Chemical Society, vol. 72, no. 12, pp. 1507-1514, 2007.

[28] K. Yokota, T. Hirabayashi, and T. Takashima, "The preparation of poly(itaconic acid)," Die Makromolekulare Chemie, vol. 176, no. 5, pp. 1197-1205, 1975.

[29] W. Mormann and J. Ferbitz, "Copolymers from _tert_ -butyl methacrylate and itaconic anhydride-reactivity ratios and polymer analogous reactions," European Polymer Journal, vol. 39, no. 3, pp. 489-496, 2003.

[30] T. Otsu and J.-Z. Yang, "Radical polymerization of itaconic anhydride and reactions of the resulting polymers with amines and alcohols," Polymer International, vol. 25, no. 4, pp. 245251, 1991.

[31] A. F. Miles and J. M. G. Cowie, "Preparation and characterization of (monomethyl itaconate)-(methyl methacrylate) and of (itaconic anhydride)-(methyl methacrylate) copolymers," European Polymer Journal, vol. 27, no. 2, pp. 165-170, 1991.

[32] B. E. Tate, "Polymerization of itaconic acid and derivatives," in Fortschritte Der Hochpolymeren-Forschung, pp. 214-232, Springer, Berlin, Heidelberg, 1967, Polymerization of itaconic acid and derivatives.

[33] J. Drougas and R. L. Guile, "Copolymerization of itaconic anhydride and styrene, determination of reactivity ratios," Journal of Polymer Science, vol. 55, no. 161, pp. 297-302, 1961.

[34] M. M. Sharabash and R. L. Guile, "Copolymerization parameters of itaconic anhydride in free-radical polymerization," Journal of Macromolecular Science: Part A - Chemistry, vol. 10, no. 6, pp. 1039-1054, 1976.

[35] S. Y. Bell, J. M. G. Cowie, and I. J. McEwen, "The miscibility of copolymer blends involving the monomers itaconic anhydride, methyl methacrylate, styrene and acrylonitrile," Polymer, vol. 35, no. 4, pp. 786-790, 1994.

[36] J. Brandrup, E. H. Immergut, and E. A. Grulke, Polymer Handbook, Wiley, New York, fourth edition, 1999.

[37] D. Kim, D. Y. Lee, K. Lee, and S. Choe, "Effect of crosslinking agents on the morphology of polymer particles produced by one-step seeded polymerization," Macromolecular Research, vol. 17, no. 4, pp. 250-258, 2009.

[38] D. M. Blake, P.-C. Maness, Z. Huang, E. J. Wolfrum, J. Huang, and W. A. Jacoby, "Application of the photocatalytic chemistry of titanium dioxide to disinfection and the killing of cancer cells," Separation and Purification Methods, vol. 28, no. 1, pp. 1-50, 1999.
[39] M. H. El-Newehy, S. M. Osman, M. S. Refat, S. S. Al-Deyab, and A. El-Faham, "Microwave synthesis of copolymers based on itaconic acid moiety and their utility for scavenging of copper (II) and lead (II)," Journal of Macromolecular Science, Part $A$, vol. 52, no. 7, pp. 561-576, 2015.

[40] S. H. Khalid, M. I. Qadir, A. Massud, M. Ali, and M. H. Rasool, "Effect of degree of cross-linking on swelling and drug release behaviour of poly(methyl methacrylate-co-itaconic acid) [P(MMA/IA)] hydrogels for site specific drug delivery," Journal of Drug Delivery Science and Technology, vol. 19, no. 6, pp. 413-418, 2009.

[41] S. M. Osman, M. H. El-Newehy, S. S. Al-Deyab, and A. ElFaham, "Microwave synthesis and thermal properties of polyacrylate derivatives containing itaconic anhydride moieties," Chemistry Central Journal, vol. 6, no. 1, p. 85, 2012.

[42] E. P. Barrett, L. G. Joyner, and P. P. Halenda, "The determination of pore volume and area distributions in porous substances. i. Computations from nitrogen isotherms," Journal of the American Chemical Society, vol. 73, no. 1, pp. 373-380, 1951. 